\title{
Promotion of couples' voluntary HIV counseling and testing in Lusaka, Zambia by influence network leaders and agents
}

\author{
K Wall ${ }^{1 *}$, W Kilembe ${ }^{2}$, A Nizam , C Vwalika², M Kautzman², E Chomba², A Tichacek², G Sardar², D Casanova², \\ F Henderson ${ }^{2}$, J Mulenga ${ }^{2}$, D Kleinbaum ${ }^{1}$, S Allen $^{2}$
}

From AIDS Vaccine 2012

Boston, MA, USA. 9-12 September 2012

\section{Background}

In sub-Saharan Africa, most HIV transmissions occur in stable heterosexual relationships. Couples' voluntary HIV counseling and testing [CVCT] is an effective strategy targeting this at-risk group. This study identified predictors of successful CVCT promotion in Lusaka, Zambia.

\section{Methods}

CVCT promotions were conducted by influential network leaders [INLs] who identified agents [INAs], who in turn delivered CVCT invitations from over an 18-month period, with a mobile unit crossing over from one intervention neighborhood to another at 9 months. INA, couple, and invitation characteristics predictive of couples' testing were evaluated accounting for two-level clustering.

\section{Results}

320 INAs delivered 29,119 invitations resulting in 1727 couples testing ( $6 \%$ success rate). In multivariate analyses, INA characteristics significantly predictive of CVCT uptake included promoting in community-based (adjusted odds ratio $[\mathrm{aOR}]=1.3)$ or health $(\mathrm{aOR}=1.5)$ networks versus private networks, being employed in the sales/service industry $(\mathrm{aOR}=1.5)$ versus unskilled manual labor, owning a home $(\mathrm{aOR}=0.7)$ versus not, and testing for HIV with a partner $(\mathrm{aOR}=1.4)$ or alone $(\mathrm{aOR}=1.3)$ versus never testing. Cohabiting couples were more likely to test $(\mathrm{aOR}=1.4)$ than non-cohabiting couples. Context characteristics predictive of CVCT uptake included inviting couples $(\mathrm{aOR}=1.2)$ versus individuals, the woman $(\mathrm{aOR}=1.6)$ or couple (aOR=1.4) initiating contact versus the INA, the couple being socially acquainted with the INA $(\mathrm{aOR}=1.6)$ versus having just met, home invitation delivery $(\mathrm{aOR}=1.3)$ versus elsewhere, and easy invitation delivery $(\mathrm{aOR}=1.8)$ versus difficult as reported by the INA. Use of mobile units was very low and did not substantially contribute to CVCT service delivery.

\section{Conclusion}

This study demonstrated the ability of influential people to promote CVCT and identified agent, couple, and contextlevel predictors of CVCT uptake in Lusaka, Zambia. We encourage the development of CVCT promotions in other sub-Saharan African countries to support sustained CVCT dissemination.

\section{Author details}

${ }^{1}$ Emory University, Atlanta, GA, USA. ${ }^{2}$ Rwanda Zambia HIV Research Group, Atlanta, GA, USA.

Published: 13 September 2012

doi:10.1186/1742-4690-9-S2-P210

Cite this article as: Wall et al:: Promotion of couples' voluntary HIV

counseling and testing in Lusaka, Zambia by influence network leaders and agents. Retrovirology 2012 9(Suppl 2):P210.

${ }^{1}$ Emory University, Atlanta, GA, USA

Full list of author information is available at the end of the article

(c) 2012 Wall et al; licensee BioMed Central Ltd. This is an Open Access article distributed under the terms of the Creative Commons 